\title{
Urocortin-dependent effects on adrenal morphology, growth, and expression of steroidogenic enzymes in vivo
}

\author{
Anna Riester, Ariadni Spyroglou, Adi Neufeld-Cohen ${ }^{1}$, Alon Chen ${ }^{1}$ \\ and Felix Beuschlein
}

Endocrine Research Unit, Medizinische Klinik und Poliklinik IV, Hospital of the Ludwig Maximilians University, Ziemssenstrasse 1, D-80336 Munich, Germany

${ }^{1}$ Department of Neurobiology, Weizmann Institute of Science, Rehovot, Israel

(Correspondence should be addressed to F Beuschlein; Email: felix.beuschlein @med.uni-muenchen.de)

\begin{abstract}
Urocortin (UCN) 1, 2, and 3 are members of the corticotropin-releasing factor (CRF) family that display varying affinities to the CRF receptor 1 (CRFR1 (CRHR1)) and 2 (CRFR2 (CRHR2)). UCNs represent important modulators of stress responses and are involved in the control of anxiety and related disorders. In addition to the CNS, UCNs and CRFRs are highly expressed in several tissues including the adrenal gland, indicating the presence of UCN-dependent regulatory mechanisms in these peripheral organ systems. Using knockout (KO) mouse models lacking single or multiple Ucn genes, we examined the potential role of the three different Ucns on morphology and function of the adrenal gland. Adrenal morphology was investigated, organ size, cell size, and number were quantified, and growth kinetics were studied by proliferative cell nuclear antigen staining and Ccnd1 expression analysis. Furthermore, mRNA expression of enzymes involved in steroidogenesis and catecholamine synthesis was quantified by real-time PCR. Following this approach, Ucn2, Ucn1/Ucn2 dKO and Ucn1/Ucn2/Ucn3 tKO animals showed a significant cellular hypotrophy of the adrenal cortex and an increase in Ccnd1 expression, whereas in all other genotypes, no changes were observable in comparison to age-matched controls. For steroidogenesis, Ucn2/Ucn3 dKO animals displayed the most pronounced changes, with significant increases in all investigated enzymes, providing indirect evidence for increased stress behavior. Taken together, these data suggest that mainly Ucn2 and Ucn3 could be involved in adrenal stress response regulation while Ucn2 additionally appears to play a role in morphology and growth of the adrenal gland.
\end{abstract}

Journal of Molecular Endocrinology (2012) 48, 159-167

\section{Introduction}

Corticotropin-releasing factor (CRF) was the first identified member of the CRF family and has been determined as the main mediator for stress responsedependent activation of the hypothalamus-pituitaryadrenal (HPA) axis (Vale et al. 1981, 1983). The neuropeptides urocortin 1 (UCN1), UCN2 (stresscopin-related peptide), and UCN3 (stresscopin) have been described more recently as additional members of the CRF family. Ucn 1 was first reported in 1995 in the rat midbrain region (Vaughan et al. 1995), while Ucn2 and Ucn3 were identified on the basis of sequence homology searching tools not until 2001 (Reyes et al. 2001). CRF, UCNs, and their receptors are involved in homeostatic mechanisms of the stress response and in the control of anxiety, cognitive functions, appetite, and related disorders (Fekete \& Zorrilla 2007).

The effects of CRF and UCNs are mediated via two G-coupled receptors, CRFR1 (CRHR1) and CRFR2 (CRHR2), which share $71 \%$ amino acid sequence similarity (Grigoriadis et al. 1996). CRFR1 and CRFR2 signal largely by coupling to Gs, leading to the stimulation of adenyl cyclase and activation of protein kinase A. However, stimulation of specific CRFRs in distinct tissues or cell types by receptor-selective CRF peptides has been demonstrated to activate a variety of further signaling pathways (Brar et al. 2002, Bale 2005). UCN1 has similar binding affinity to CRFR1 and CRFR2 while UCN2 and UCN3 are considered as specific ligands for CRFR2 (Fukuda et al. 2005). These specific binding properties translate into distinct phenotypic changes induced by targeted deletions of the CRF receptors. Animals deficient for CRFR1 have an impaired stress response (Smith et al. 1998, Timpl et al. 1998) and decreased anxiety-like behavior (Smith et al. 1998) and fail to display the characteristic HPA axis response to restraint stress. In contrast, Crfr2-mutant mice display increased anxiety-like behavior and are hypersensitive to stressors (Bale et al. 2000, Coste et al. 2000).

In addition to the well-characterized effects of Ucns in the CNS, over the last few years, a number of peripheral sites of action have been identified.

DOI: 10.1530/JME-11-0144 Online version via http://www.endocrinology-journals.org 
Ucn1 expression has been observed in adipocytes (Seres et al. 2004), heart (Nishikimi et al. 2000), skin, and immunological tissue including the thymus and spleen, among others (Baigent 2001). Ucn2 is highly expressed in skin and skeletal muscle, and is differently regulated by circulating glucocorticoid levels, as manipulated by exogenous administration or adrenalectomy (Chen et al. 2004). Ucn3 gene expression can be detected in pancreatic $\beta$ cells, where it stimulates insulin and glucagon secretion (Li et al. 2003), and in the adipose tissue, heart, and skin. CRFR2 is broadly distributed in peripheral tissues including the heart and skeletal muscle (Dautzenberg \& Hauger 2002, Suda et al. 2004). In addition to the expression of CRFR1 in different sites of the brain (Justice et al. 2008), Crfrl expression could be documented in many peripheral tissues such as the testis, endocrine pancreas, or colon (Tao et al. 2007, Huising et al. 2010, O'Malley et al. 2010). Similar to other peripheral organs, members of the CRF/UCN system are also present in the adrenal gland, with Ucn2 and Ucn3 as well as CRFR2 being predominantly expressed in the adrenal cortex, while Ucn1 and CRFR1 are mainly detectable in the adrenal medulla, and CRF is distributed throughout the adrenal gland. A proposed intra-adrenal UCN-dependent regulatory system would thus be dependent on the balance between the local concentration of CRF and UCNs and the presence of their receptors. Following this notion, it has been suggested that a CRFR1 receptor/ ligand system might be active in the medulla, while a parallel CRFR2 receptor/ligand system might modulate adrenocortical function (Tsatsanis et al. 2007). Some examples provide evidence for a functional significance of a local UCN system within the adrenal gland: human fetal adrenal cells are able to respond to CRF stimulation through activation of CRFR1 with an increase in steroidogenesis, which has been hypothesized to be required for the late gestational increase in fetal adrenal cortisol and DHEAS production (Sirianni et al. 2005). In addition, preliminary data suggest a stress-related upregulation of Ucn 2 in the adrenal gland (Liu et al. 2008).

However, the physiological role of the influence of Ucns on adrenal function and structure has not been investigated in depth so far. Thus, our approach was to investigate the effects of the three Ucns on the adrenal gland using six different $U c n$-knockout (KO) mouse models: individual $\mathrm{KO}$ for each one of the three peptides genes (Ucn1 KO, Ucn2 $\mathrm{KO}$, and Ucn3 $\mathrm{KO}$ ) as well as combined deletions of two (Ucn1/Ucn2 $\mathrm{KO}$ and Ucn2/Ucn3 $\mathrm{dKO}$ ) or all the three Ucns (Ucn1/ Ucn $2 / U c n 3 \mathrm{tKO})$. To achieve this goal, we investigated the mRNA expression of enzymes involved in steroidogenesis and catecholamine production as well as the histological appearance of the adrenal gland of those mouse models.

\section{Materials and methods}

\section{Animals and housing conditions}

For the animal experiments, six different genotypes of male Ucn KO mice were used. Mouse breeding took place at the Weizmann Institute of Science, Rehovot, Israel. Mice lacking two or all the three Ucn genes (Ucn1, Ucn2, and Ucn3) were generated by crossbreeding of Ucn1, Ucn2, and Ucn3 single KO mice, which has been reported earlier (Vetter et al. 2002, Chen et al. 2006, Neufeld-Cohen et al. 2010a,b). All mice were on a mixed C57BL $/ 6 \times 129$ background. WT mice of the mixed C57BL/ $6 \times 129$ background were derived from the same breeding colony. Male mice that were used in this study were housed up to five mice per cage on a $12 \mathrm{~h}$ light: $12 \mathrm{~h}$ darkness photoperiod (lights on at $1800 \mathrm{~h}$ ) with food and water ad libitum. All experimental protocols were approved by the Institutional Animal Care and Use Committee of The Weizmann Institute of Science.

To exclude interferences due to the female estrous cycle, as documented earlier (Chen et al. 2006, Xu et al. 2006), only male mice were investigated. Ucn1 KO $(n=10)$, Ucn $2 \mathrm{KO}(n=9), U c n 3 \mathrm{KO}(n=9), U c n 1 / U c n 2$ dKO $(n=8), U c n 2 / U c n 3 \mathrm{dKO}(n=11), U c n 1 / U c n 2 /$ Ucn 3 tKO $(n=8)$, and WT controls $(n=11)$ were killed at the age of 3 months.

\section{Morphometry and immunohistochemistry}

Adrenal glands from all investigated genotypes were rapidly dissected and placed in $4 \%$ paraformaldehyde overnight. Tissues were dehydrated, embedded in paraffin, sectioned, and stained with hematoxylin and eosin (H\&E) following standard protocols. H\&Estained adrenal sections were examined using a light microscope with a magnification of $40 \times$ and $400 \times$. Areas of medulla and cortex were quantified on four independent sections per mouse from the center of the adrenal gland using the SpotAdvanced Software (Spot, Burroughs, Sterling Heights, MI, USA). The medullary area was normalized for the cortical area and expressed as the medullary/cortical area ratio. Cell nuclei within the outer and inner adrenal cortex were counted on three independent sections per animal under standardized conditions. A decrease in cell size was defined as cellular hypotrophy, whereas a decrease in nuclear density was interpreted as evidence of cellular hypertrophy, as the amount of extracellular matrix was comparable between the lines. In the adrenal cortex, less cytoplasm can be regarded as a rough estimate of lower functional activity of the cells. Cell counts were expressed as cell number/high power field (ncl/hpf). For proliferative cell nuclear antigen (PCNA) immunohistochemistry (IHC), paraffin-embedded sections 
were rehydrated, blocked with $0 \cdot 3 \% \mathrm{H}_{2} \mathrm{O}_{2}$ in methanol for $10 \mathrm{~min}$, and incubated with blocking buffer for $15 \mathrm{~min}$. PCNA was immunolocalized overnight at $4{ }^{\circ} \mathrm{C}$ by means of a rabbit polyclonal antibody (Santa Cruz Biotechnology, Santa Cruz, CA, USA) in a dilution of 1:100 in blocking buffer containing 3\% BSA (Roche Applied Science), 5\% goat serum (Jackson ImmunoResearch Laboratories, West Grove, PA, USA), and $0.5 \%$ Tween 20. After rinsing for $15 \mathrm{~min}$ in PBS, secondary antibody (goat-anti-rabbit-biotinylated IgG (Vector Laboratories, Burlingame, CA, USA)) in a dilution of 1:200 in blocking buffer was applied for $30 \mathrm{~min}$ at room temperature. For the visualization of the bound PCNA antibody, Vectastain Elite ABC system (Vector Laboratories) and Sigma Fast diaminobenzidine (Sigma) were used.

\section{Quantitative real-time PCR}

Adrenal glands from mice of all investigated genotypes were immediately cleansed of adjacent tissue under a stereo microscope, snap frozen in liquid nitrogen, and stored at $-80^{\circ} \mathrm{C}$. Both adrenals from each individual animal were combined and homogenized in extraction buffer while still frozen. RNA was extracted using the SV Total RNA Isolation System according to the manufacturer's instructions (Promega). RNA quality was verified on a $1.5 \%$ agarose gel. For cDNA synthesis, $500 \mathrm{ng}$ total RNA were reverse transcribed using the reverse transcription system (Promega).

Gene expression of selected genes involved in steroidogenesis, catecholamine production, and cell cycle regulation was investigated: steroidogenic acute regulatory protein (Star), cholesterol side-chain cleavage enzyme $(C y p 11 a 1), 11$-b-hydroxylase $(C y p 11 b 1)$, aldosterone synthase (Cyp11b2), tyrosine hydroxylase (Th), phenylethanolamine $\mathrm{N}$-methyltransferase $(\mathrm{Pnmt})$, and cyclin D1 (Ccnd1). $\beta$-Actin was used as housekeeping gene. For primer sequences, see Table 1.

Quantification of $\beta$-actin, Star, Cyp11a1, and Cyp11b2 was accomplished for all genotypes using the FastStart DNA MasterPlus SYBR Green I reaction mix in the LightCycler 1.5 (Roche). Real-time PCR conditions in the LightCycler were preincubation at $95^{\circ} \mathrm{C}$ for $10 \mathrm{~min}$ followed by amplification of 40 cycles at $95^{\circ} \mathrm{C}$ for $10 \mathrm{~s}$, the annealing temperature (primer dependent, see Table 1) for $5 \mathrm{~s}$, and extension at $72^{\circ} \mathrm{C}$, at which the time is calculated by the product length in base pairs divided by 25 . The melting curve analysis was performed between 65 and $95^{\circ} \mathrm{C}\left(0 \cdot 1^{\circ} \mathrm{C} / \mathrm{s}\right)$. For the quantification of Cyp11b1, Th, Pnmt, and Ccnd1, the Sso Fast EVA Green Supermix (Bio-Rad Laboratories) in the Mx3000P QPCR System (Stratagene, La Jolla, CA, USA) was used. Real-time PCR conditions were preincubation at $95^{\circ} \mathrm{C}$ for 10 min followed by amplification of 40 cycles at $95^{\circ} \mathrm{C}$ for $10 \mathrm{~s}$, the annealing temperature for $5 \mathrm{~s}$ (primer dependent, see Table 1), and extension at $72^{\circ} \mathrm{C}$. The melting curve analysis was performed between 65 and $95^{\circ} \mathrm{C}\left(0 \cdot 1{ }^{\circ} \mathrm{C} / \mathrm{s}\right)$.

Furthermore, all products were run on a $1 \%$ agarose gel to verify the correct size of the amplified product. Quantification was adjusted using the housekeeping gene $\beta$-actin. To facilitate overall comparison of individual real-time experiments, expression levels of the particular genes were set as $100 \%$ for WT animals.

\section{Statistical analysis}

All results are expressed as mean \pm s.E.M. Statistical significance was determined using the Mann-Whitney $U$ test with the Prism 3.02 Software (GraphPad Software, La Jolla, CA, USA). Statistical significance was defined as $P<0 \cdot 05$.

Table 1 Primer sequences

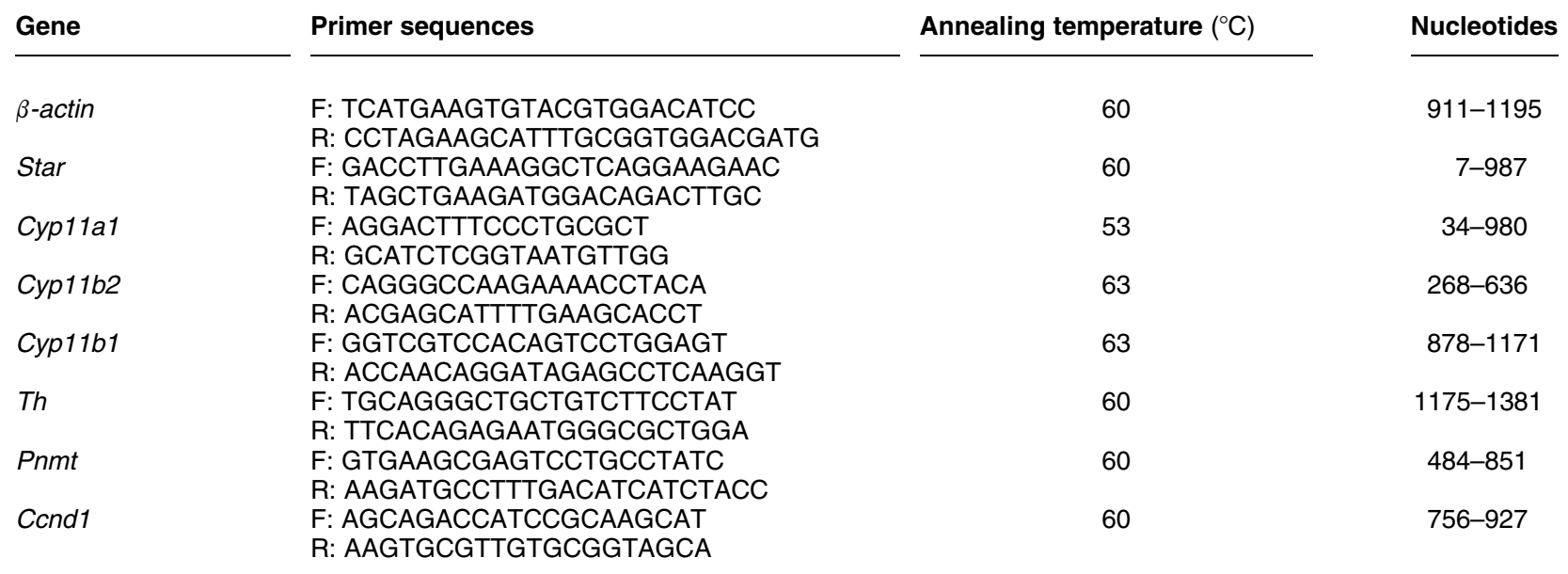



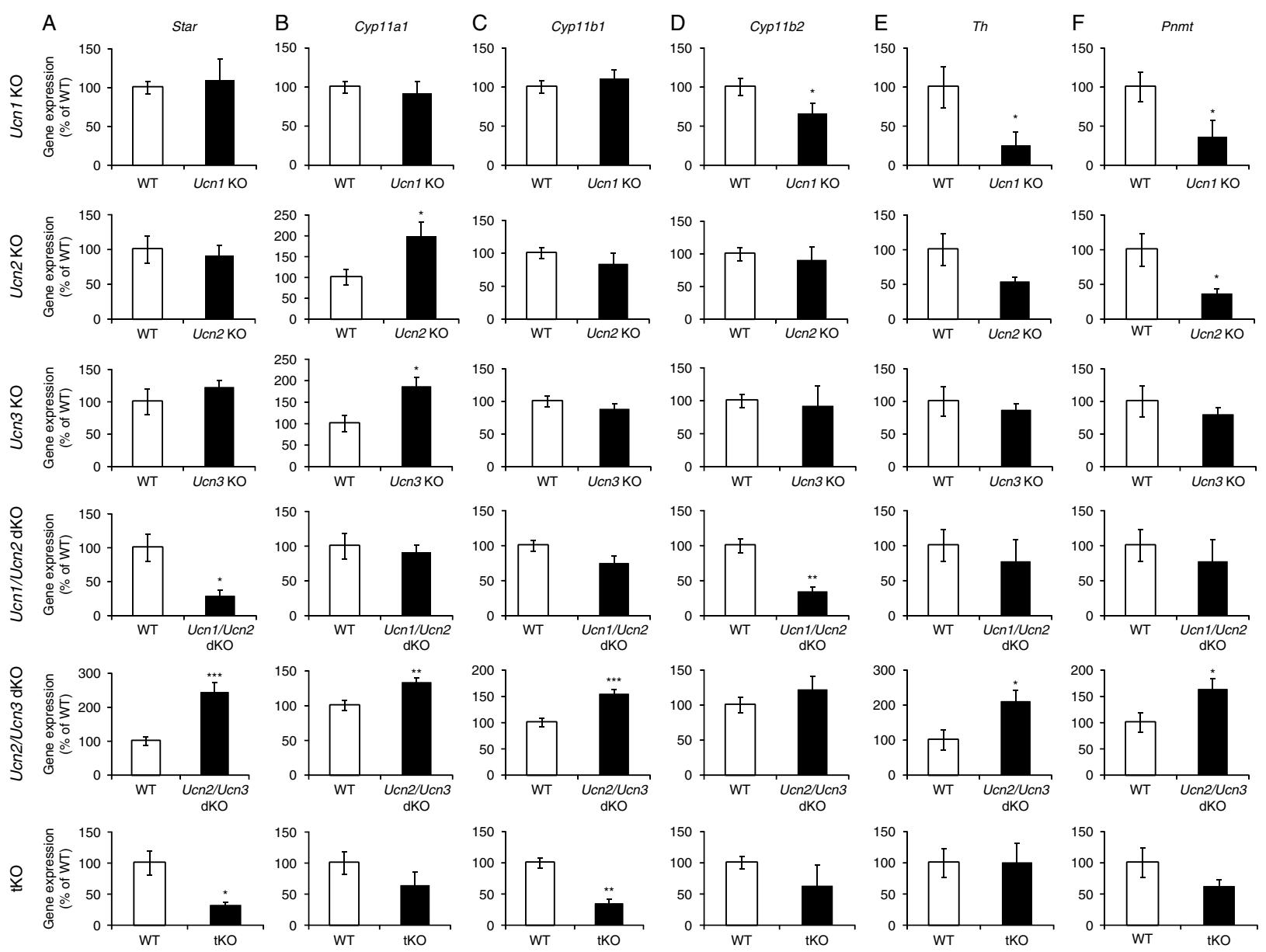

Figure 1 Gene expression levels of enzymes involved in steroidogenesis: Star (A), Cyp11a1 (B), Cyp11b1 (C), and Cyp11b2 (D) and in catecholamine synthesis: Th (E) and Pnmt (F) in the adrenal gland of Ucn1 KO, Ucn2 KO, Ucn3 KO, Ucn1/Ucn2 dKO, Ucn2/Ucn3 dKO, and Ucn 1/Ucn2/Ucn3 tKO mice. Asterisks denote significant changes for each gene over WT expression levels that are set as $100 \%$ for each gene.

\section{Results}

\section{Ucn1 KO}

The area of the adrenal gland and the cortical/medullary area ratio showed no differences between Ucn1 KO mice and WT controls. Morphometrical studies of the outer adrenal cortex displayed a significant increase in nuclei per $\mathrm{hpf}(\mathrm{ncl} / \mathrm{hpf})$ in Ucnl $\mathrm{KO}$ mice in comparison with age-matched WT controls, indicating cellular hypotrophy. In the inner adrenal cortex, no structural differences in comparison with WT animals could be observed. On the molecular level, Ucn1 KO mice displayed a significant decrease in Cyp11b2 expression, but there was no significant differences in the expression of Star, Cyp11a1, or Cyp11b1. Investigation of the expression pattern of enzymes of the adrenal medulla, involved in catecholamine synthesis, showed a significantly lower Th and Pnmt expression in
Ucn1 KO mice (Fig. 1). Cell proliferation, assessed by IHC with PCNA, did not demonstrate any differences in the staining intensity between Ucn1 KO and WT mice. Cell cycle activation was quantified with Cond1 expression, but again no changes could be documented in the Ucn1 KO animals (Fig. 2).

\section{Ucn2 KO}

Ucn $2 \mathrm{KO}$ mice had a significantly higher cell number per hpf in the adrenal cortex in comparison with WT animals. In contrast to the cellular hypotrophy, no changes in the area of the adrenal gland or the ratio between cortex and medulla could be found. On the molecular level, a pronounced upregulation of Cyp11a1 expression in Ucn2 $\mathrm{KO}$ animals was observed. In contrast, expression levels of Star, Cyp11b1, and Cyp11b2 remained unchanged. As for the adrenal 


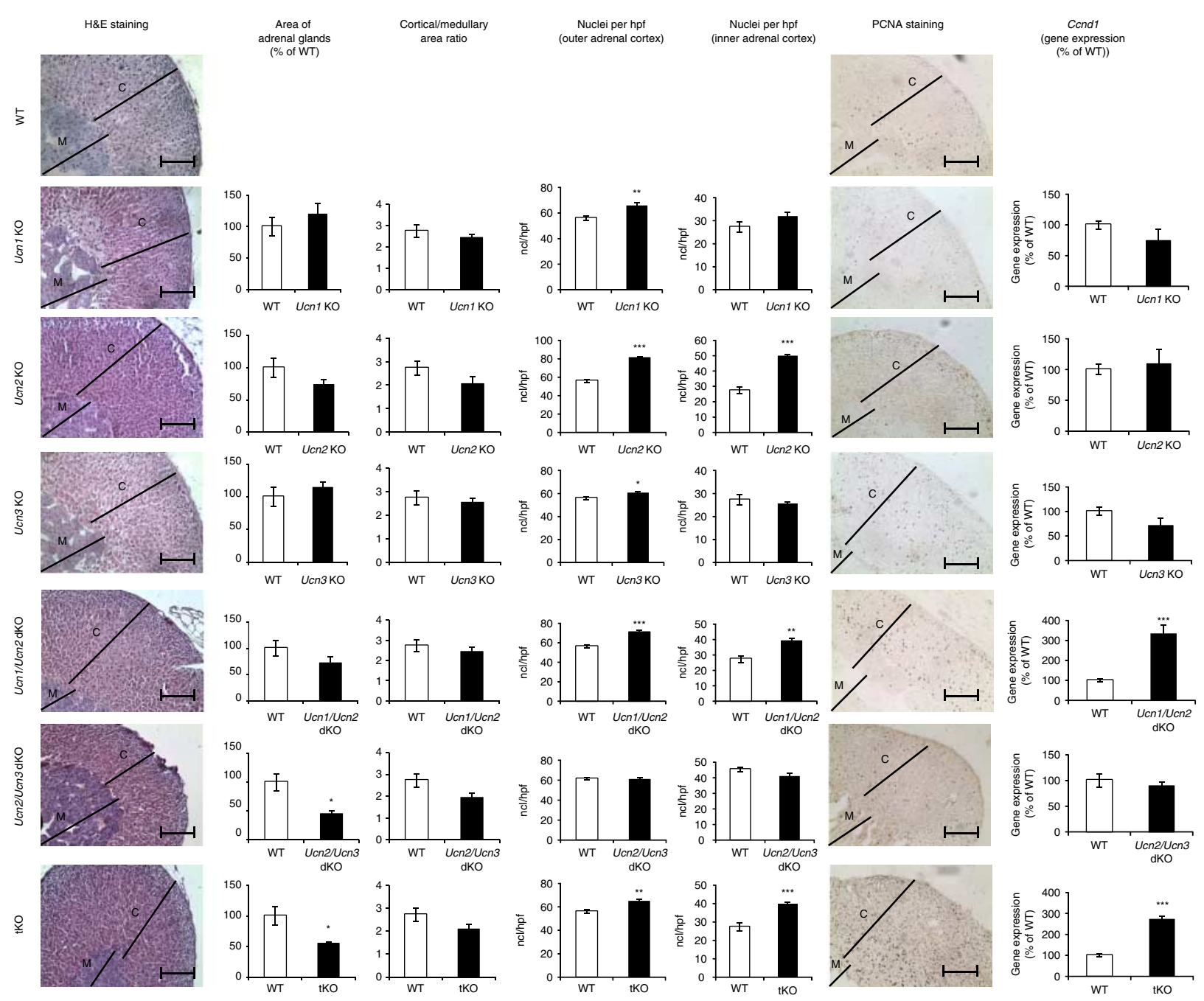

Figure 2 Representative H\&E staining out of the center of the adrenal glands of all genotypes investigated. M, adrenal medulla; $\mathrm{C}$, adrenal cortex, scale bar represents $50 \mu \mathrm{m}$; area of the adrenal gland, cortical/medullary area ratio, and morphometrical studies of the outer and inner adrenal cortex of Ucn $1 \mathrm{KO}, U c n 2 \mathrm{KO}, U c n 3 \mathrm{KO}, U c n 1 / U c n 2 \mathrm{dKO}, U c n 2 / U c n 3 \mathrm{dKO}$, and Ucn 1/Ucn2/Ucn3 tKO mice in comparison with age-matched WT animals; representative PCNA staining of all phenotypes investigated; and Ccnd1 expression levels of Ucn $1 \mathrm{KO}, U c n 2 \mathrm{KO}, U c n 3 \mathrm{KO}, U c n 1 / U c n 2 \mathrm{dKO}, U c n 2 / U c n 3 \mathrm{dKO}$, and Ucn 1/Ucn2/Ucn3 tKO mice. Asterisks denote significant changes for each gene over WT expression levels that are set as $100 \%$ for each gene. Full colour version of this figure available via http://dx.doi.org/10.1530/JME-11-0144.

medulla, Pnmt expression was found to be significantly lower in Ucn2 $\mathrm{KO}$ mice, whereas Th expression did not differ significantly between the two investigated groups showing, though, the same tendency (Fig. 1). Cell proliferation assessed by Ccnd1 expression remained unchanged in this KO model (Fig. 2).

\section{Ucn3 KO}

Analysis of the structure of adrenal cortices of $\operatorname{Ucn} 3 \mathrm{KO}$ mice displayed a higher number of cells per hpf in the outer adrenal cortex in comparison with WTanimals. In contrast, the cell number of the inner adrenal cortex was comparable between the two groups as well as the size of the adrenal and the cortical/medullary area ratio. Similarly, expression levels of Star, Cyp11b1, and Cyp11b2 did not differ between Ucn3 KO and WT mice. However, elevated levels of Cyp11a1 expression in Ucn3 KO animals could be observed. Th and Pnmt expression did not differ between Ucn3 KO and WT mice (Fig. 1). Ccnd1 levels showed a trend toward reduced expression, but PCNA staining did not reveal any changes in the proliferation rate in $U c n 3 \mathrm{KO}$ animals (Fig. 2).

\section{Ucn1/Ucn2 dKO}

Ucn1/Ucn2 dKO mice displayed no differences in the area of the adrenal gland and in cortical/medullary 
area ratio in comparison with WT controls. However, Ucn1/Ucn2 dKO mice had a significantly higher cell number per hpf in the outer and inner adrenal cortex, indicating cellular hypotrophy. Significantly lower levels of expression for Star and Cyp11b2 were found in adrenals from Ucn1/Ucn2 dKO mice in comparison with WT controls. In contrast, Cyp11a1 and Cyp11b1 expressions were comparable between the two groups, with no significant difference between WT and Ucn 1/Ucn2 dKO animals. Both Th and Pnmt expression levels, involved in catecholamine production, showed no differences in the Ucn1/Ucn2 dKO mice (Fig. 1). Cell proliferation proved to be significantly higher in Ucn 1/Ucn2 dKO mice. Likewise, IHC with PCNA presented an increased staining in both the medulla and cortex of those mice (Fig. 2).

\section{Ucn2/Ucn3 dKO}

Mice lacking both Ucn2 and Ucn3 displayed no significant differences in morphological studies of the adrenal cortex by counting the cell number per hpf in comparison with WT controls. However, Ucn2/Ucn3 dKO mice displayed smaller adrenal glands with an unchanged ratio of the cortex to medulla area in comparison with WT animals. In contrast, significant upregulation of Star, Cyp11a1, and Cyp11b1 could be shown. Cyp1 1 b2 levels did not differ between Ucn2/Ucn3 dKO mice and WT controls. Ucn2/Ucn3 dKO mice presented a significant upregulation of the expression levels of enzymes catalyzing catecholamine synthesis (Fig. 1). No changes in the Condl levels could be observed in this investigated group, similarly as after PCNA IHC staining (Fig. 2).

\section{Ucn1/Ucn2/Ucn3 tKO}

Following morphometrical analyses, adrenals from tKO mice had a significantly higher cell number per hpf in the inner and outer adrenal cortex. Besides the cellular hypotrophy, a reduced surface of the adrenal gland could be found in comparison with WT controls. However, the medulla/cortex area ratio displayed no differences between triple KO and WT mice. Significantly lower expression levels of Star and Cyp11b1 in the adrenal were evident in tKO animals when compared with WT controls while differences in Cyp11a1 and Cyp11b2 displayed the same trend but failed to reach statistical significance. Adrenal medulla enzymes showed no changes in their expression levels between tKO mice and WT controls (Fig. 1). Adrenal glands of tKO animals displayed a significant increase in the cell cycle protein CCND1. Accordingly, an increased IHC staining with PCNA could be documented in the adrenals of those animals (Fig. 2).

\section{Discussion}

To evaluate the impact of the three different UCNs on the adrenal gland in an in vivo situation, we made use of six UCN KO models and investigated the effect of these targeted deletions on adrenal structure and function. Following this morphological and molecular approach, it became evident that absence of specific UCNs results in a complex pattern of functional changes in the adrenal gland, which would not have been predicted in all instances.

Ucn1 and Ucn2 have been implicated in fluid and sodium regulation and modulation of cardiac function during heart failure. Specifically, administration of Ucn1 in a sheep model with acute heart failure has been reported to result in decreasing levels of plasma vasopressin, renin activity, as well as aldosterone and natriuretic peptide levels (Rademaker et al. 2002), which was associated with delayed development of overt heart failure (Rademaker et al. 2007). Similarly, Ucn2 was shown to reverse furosemide-induced increases in plasma renin activity and induced greater decreases in plasma aldosterone and vasopressin (Rademaker $e$ t al. 2009). While these effects involve multiple systems including cardiac and vascular function, there is only limited information on UCN-dependent adrenocortical aldosterone secretion. Interestingly, in vitro treatment of the human adrenocortical cell line NCIh295 with Ucn1 has been demonstrated to induce and increase in Cyp11b2 expression and aldosterone secretion (Kageyama et al. 2010). In line with this finding in our KO model, lack of Ucn1 and Ucn2 alone or in combination was associated with cellular hypotrophy of the outer adrenal cortex and lower expression levels of Cyp11b2. Thus, while the interventional protocols using Ucn 1 and Ucn 2 in models of heart failure demonstrate an inhibition of several volume-retaining hormones including the renin-angiotensin aldosterone system, direct effects on aldosterone secretion from the adrenal cortex cannot be excluded and might impact on long-term effects of these peptides.

In previous studies, it has been described that Ucn1 KO mice display normal hormonal responses to acute stress (Vetter et al. 2002, Wang et al. 2002). In accordance with these findings, we demonstrated that the structure of the inner adrenal cortex as well as the expression levels of the enzymes involved in corticosterone and catecholamine synthesis remained unchanged. As Crfrl KO mice have been reported to have an atrophic adrenal medulla and lower epinephrine plasma levels (Yoshida-Hiroi et al. 2002), it is prudent to assume that functional redundancy through retained CRF-dependent stimulation of the CRFR1 could be the reason for the observed minor effects on zona fasciculata function but not for the significant effects in adrenomedullary function in $U c n 1 \mathrm{KO}$ animals. 
In previous experiments, we could demonstrate that female, but not male, Ucn $2 \mathrm{KO}$ mice exhibit an increase in the basal daily rhythm of ACTH and corticosterone (Chen et al. 2006). These findings are endorsed by our present studies in which the absence of Ucn 2 caused cellular hypotrophy of the adrenal cortex in male animals with only minor differences in the expression of steroidogenic enzymes and enzymes involved in catecholamine synthesis. Almost identically, in Ucn $3 \mathrm{KO}$ mice, no or only small differences regarding adrenal structure, steroidogenesis, and epinephrine synthesis were detectable, a finding that also correlates with earlier data demonstrating normal corticosterone values in Ucn3 KO animals (Deussing et al. 2010). Similar to the situation in single Ucn1 KO animals, it is well possible that the isolated lack of one of both UCNs acting via the CRFR2 might be compensated by the other, resulting in a rather mild phenotype in single Ucn 2 and Ucn $3 \mathrm{KO}$ mice.

In line with this notion and in contrast to the isolated KO models, mice lacking both Ucn2 and Ucn3 showed a robust upregulation of all investigated enzymes of steroidogenesis and catecholamine synthesis and displayed smaller adrenal glands, whereas no structural differences on cellular level or on proliferation could be observed. Accordingly, the increase in Star expression in Ucn $2 / U_{c n} 3 \mathrm{dKO}$ animals could be explained by the dominance of the stress phenotype of Ucn1 peptide in this model leading to increased steroidogenesis. Similarly, in each of the Ucn2 and Ucn 3 $\mathrm{KO}$ and more pronounced in the Ucn $2 / U_{c n} 3 \mathrm{dKO}$ model, the dominance of the Ucn1 peptide was associated with an increase in Cyp11a1. For Cyp11b1, although the expression data were not significantly different in the single $\mathrm{KO}$ animals as expected, its expression was significantly upregulated in Ucn2/Ucn3 $\mathrm{dKO}$ mice and on the other hand significantly downregulated in Ucn1/Ucn2/Ucn3 tKO animals. Consequently, Ucn1 appears not to contribute to a rescue of the stress-coping phenotype, as described earlier, although it is known that it has a similar affinity to both CRF receptors. It has been previously shown that $\mathrm{Crfr} 2 \mathrm{KO}$ mice display normal baseline concentrations of ACTH and corticosterone but increased sensitivity to stress (Bale et al. 2000, Coste et al. 2000, 2006), supporting the hypothesis that stimulation of CRFR2 results in a decrease in anxiety and to a stress-coping behavior (Hsu \& Hsueh 2001).

In Ucn 1/Ucn2/Ucn3 tKO mice, a decrease in adrenal size, cellular hypotrophy of the adrenal cortex, reduced steroidogenic capacity, and increased proliferation rate were observable, indicating that absence of Ucn 1 outweighs the lack of Ucn2 and Ucn3. However, Ucn 1 is mainly expressed in the adrenal medulla and functions via binding to its receptors CRFR1 and CRFR2, which are mainly located in the adrenal cortex.
A possible model of indirect or direct interaction between the adrenal cortex and the medulla has been proposed, for example, by Fukuda et al. (2005). Comparable to this phenotype is the $\mathrm{Crfrl} / 2 \mathrm{KO}$ model described previously, where an atrophy of the zona fasciculata and a phenotype of glucocorticoid insufficiency could be documented (Preil et al. 2001). Apparently, absence of either all three UCNs or both their receptors from the adrenal gland leads to a similar phenotypic development of the organ structure. Concordant with the reduced levels of steroidogenic enzymes in triple $\mathrm{KO}$ animals is the observation that Ucn 1/Ucn 2/Ucn3 tKO mice show a tendency toward reduced corticosterone levels under baseline conditions (Neufeld-Cohen et al. 2010b), although the adrenal insufficiency appears to be less pronounced in this model in comparison with $C R F 1 / 2 \mathrm{KO}$ animals.

Finally, in Ucn1/Ucn $2 \mathrm{dKO}$ mice, significant downregulation of key enzymes of steroidogenesis was detectable, together with a significant cellular hypotrophy of the adrenal cortex and an increased proliferation rate. As this observation is not in absolute agreement with a recent study, in which older animals had been investigated (Neufeld-Cohen et al. 2010a), an explanation for this discrepancy could be that UCN-mediated effects display age dependency. While a number of parameters affecting adrenal formation and zonation have been found to be age dependent (Bielohuby et al. 2007, Hershkovitz et al. 2007), UCN-related effects on the adrenal glands will require further detailed experiments involving time-dependent functional studies. The fact that Ucn1/Ucn2-dependent phenotype is comparable with that of Ucn1/Ucn2/Ucn3 tKO mice, together with the very slight changes observed in Ucn 3 single KO mice suggest that the role of Ucn3 on adrenal function and growth is relatively limited. Additionally, as only in Ucn2 KO, Ucn 1/Ucn $2 \mathrm{dKO}$, and Ucn 1/Ucn2/Ucn3 tKO animals a cellular hypotrophy of the adrenal cortex could be documented, a potential role of Ucn2 in the development and the structure of the adrenal gland can be hypothesized.

Taken together, the absence of UCNs influences both the adrenal cortex and the medulla. As UCN single KO mice showed relatively mild adrenal phenotypes, these findings suggest that regulation of adrenal structure and function is dependent on the balance of all UCNs and their receptors.

\section{Declaration of interest}

The authors declare that there is no conflict of interest that could be perceived as prejudicing the impartiality of the research reported. 


\section{Funding}

This work was supported by grants from the German-Israeli Foundation (925-173.2/2006) to F B and A C.

\section{Acknowledgements}

The authors would like to thank Prof. Wylie Vale, The Salk Institute for Biological Studies, La Jolla, CA for the permission to use the Ucn KO mice for this study.

\section{References}

Baigent SM 2001 Peripheral corticotropin-releasing hormone and urocortin in the control of the immune response. Peptides $\mathbf{2 2}$ 809-820. (doi:10.1016/S0196-9781(01)00395-3)

Bale TL 2005 Sensitivity to stress: dysregulation of CRF pathways and disease development. Hormones and Behavior 48 1-10. (doi:10.1016/ j.yhbeh.2005.01.009)

Bale TL, Contarino A, Smith GW, Chan R, Gold LH, Sawchenko PE, Koob GF, Vale WW \& Lee KF 2000 Mice deficient for corticotropinreleasing hormone receptor-2 display anxiety-like behaviour and are hypersensitive to stress. Nature Genetics 24 410-414. (doi:10. 1038/74263)

Bielohuby M, Herbach N, Wanke R, Maser-Gluth C, Beuschlein F, Wolf E \& Hoeflich A 2007 Growth analysis of the mouse adrenal gland from weaning to adulthood: time- and gender-dependent alterations of cell size and number in the cortical compartment. American Journal of Physiology. Endocrinology and Metabolism 293 E139-E146. (doi:10.1152/ajpendo.00705.2006)

Brar BK, Railson J, Stephanou A, Knight RA \& Latchman DS 2002 Urocortin increases the expression of heat shock protein 90 in rat cardiac myocytes in a MEK1/2-dependent manner. Journal of Endocrinology 172 283-293. (doi:10.1677/joe.0.1720283)

Chen A, Blount A, Vaughan J, Brar B \& Vale W 2004 Urocortin II gene is highly expressed in mouse skin and skeletal muscle tissues: localization, basal expression in corticotropin-releasing factor receptor (CRFR) 1- and CRFR2-null mice, and regulation by glucocorticoids. Endocrinology 145 2445-2457. (doi:10.1210/en. 2003-1570)

Chen A, Zorrilla E, Smith S, Rousso D, Levy C, Vaughan J, Donaldson C, Roberts A, Lee KF \& Vale W 2006 Urocortin 2-deficient mice exhibit gender-specific alterations in circadian hypothalamus-pituitaryadrenal axis and depressive-like behavior. Journal of Neuroscience 26 5500-5510. (doi:10.1523/JNEUROSCI.3955-05.2006)

Coste SC, Kesterson RA, Heldwein KA, Stevens SL, Heard AD, Hollis JH, Murray SE, Hill JK, Pantely GA, Hohimer AR et al. 2000 Abnormal adaptations to stress and impaired cardiovascular function in mice lacking corticotropin-releasing hormone receptor-2. Nature Genetics 24 403-409. (doi:10.1038/74255)

Coste SC, Heard AD, Phillips TJ \& Stenzel-Poore MP 2006 Corticotropin-releasing factor receptor type 2-deficient mice display impaired coping behaviors during stress. Genes, Brain and Behavior 5 131-138. (doi:10.1111/j.1601-183X.2005.00142.x)

Dautzenberg FM \& Hauger RL 2002 The CRF peptide family and their receptors: yet more partners discovered. Trends in Pharmacological Sciences 23 71-77. (doi:10.1016/S0165-6147(02)01946-6)

Deussing JM, Breu J, Kuhne C, Kallnik M, Bunck M, Glasl L, Yen YC, Schmidt MV, Zurmuhlen R, Vogl AM et al. 2010 Urocortin 3 modulates social discrimination abilities via corticotropin-releasing hormone receptor type 2. Journal of Neuroscience 30 9103-9116. (doi:10.1523/JNEUROSCI.1049-10.2010)
Fekete EM \& Zorrilla EP 2007 Physiology, pharmacology, and therapeutic relevance of urocortins in mammals: ancient CRF paralogs. Frontiers in Neuroendocrinology 28 1-27. (doi:10.1016/ j.yfrne.2006.09.002)

Fukuda T, Takahashi K, Suzuki T, Saruta M, Watanabe M, Nakata T \& Sasano H 2005 Urocortin 1, urocortin 3/stresscopin, and corticotropin-releasing factor receptors in human adrenal and its disorders. Journal of Clinical Endocrinology and Metabolism 90 4671-4678. (doi:10.1210/jc.2005-0090)

Grigoriadis DE, Lovenberg TW, Chalmers DT, Liaw C \& De Souze EB 1996 Characterization of corticotropin-releasing factor receptor subtypes. Annals of the New York Academy of Sciences 780 60-80. (doi:10.1111/j.1749-6632.1996.tb15112.x)

Hershkovitz L, Beuschlein F, Klammer S, Krup M \& Weinstein Y 2007 Adrenal 20alpha-hydroxysteroid dehydrogenase in the mouse catabolizes progesterone and 11-deoxycorticosterone and is restricted to the X-zone. Endocrinology 148 976-988. (doi:10.1210/ en.2006-1100)

Hsu SY \& Hsueh AJ 2001 Human stresscopin and stresscopin-related peptide are selective ligands for the type 2 corticotropin-releasing hormone receptor. Nature Medicine 7 605-611. (doi:10.1038/87936)

Huising MO, van der Meulen T, Vaughan JM, Matsumoto M, Donaldson CJ, Park H, Billestrup N \& Vale WW 2010 CRFR1 is expressed on pancreatic beta cells, promotes beta cell proliferation, and potentiates insulin secretion in a glucose-dependent manner. PNAS 107 912-917. (doi:10.1073/pnas.0913610107)

Justice NJ, Yuan ZF, Sawchenko PE \& Vale W 2008 Type 1 corticotropin-releasing factor receptor expression reported in BAC transgenic mice: implications for reconciling ligand-receptor mismatch in the central corticotropin-releasing factor system. Journal of Comparative Neurology 511 479-496. (doi:10.1002/cne. 21848)

Kageyama K, Hanada K \& Suda T 2010 Differential regulation and roles of urocortins in human adrenal H295R cells. Regulatory Peptides 162 18-25. (doi:10.1016/j.regpep.2010.02.006)

Li C, Chen P, Vaughan J, Blount A, Chen A, Jamieson PM, Rivier J, Smith MS \& Vale W 2003 Urocortin III is expressed in pancreatic beta-cells and stimulates insulin and glucagon secretion. Endocrinology 144 3216-3224. (doi:10.1210/en.2002$0087)$

Liu X, Serova L, Kvetnansky R \& Sabban EL 2008 Identifying the stress transcriptome in the adrenal medulla following acute and repeated immobilization. Annals of the New York Academy of Sciences 1148 1-28. (doi:10.1196/annals.1410.082)

Neufeld-Cohen A, Evans AK, Getselter D, Spyroglou A, Hill A, Gil S, Tsoory M, Beuschlein F, Lowry CA, Vale W et al. 2010 a Urocortin-1 and -2 double-deficient mice show robust anxiolytic phenotype and modified serotonergic activity in anxiety circuits. Molecular Psychiatry 15 426-441, 339. (doi:10.1038/mp.2009.115)

Neufeld-Cohen A, Tsoory MM, Evans AK, Getselter D, Gil S, Lowry CA, Vale WW \& Chen A 2010b A triple urocortin knockout mouse model reveals an essential role for urocortins in stress recovery. PNAS 107 19020-19025. (doi:10.1073/pnas.1013761107)

Nishikimi T, Miyata A, Horio T, Yoshihara F, Nagaya N, Takishita S, Yutani C, Matsuo H, Matsuoka H \& Kangawa K 2000 Urocortin, a member of the corticotropin-releasing factor family, in normal and diseased heart. American Journal of Physiology. Heart and Circulatory Physiology 279 H3031-H3039.

O'Malley D, Dinan TG \& Cryan JF 2010 Alterations in colonic corticotropin-releasing factor receptors in the maternally separated rat model of irritable bowel syndrome: differential effects of acute psychological and physical stressors. Peptides 31 662-670. (doi:10.1016/j.peptides.2010.01.004)

Preil J, Muller MB, Gesing A, Reul JM, Sillaber I, van Gaalen MM, Landgrebe J, Holsboer F, Stenzel-Poore M \& Wurst W 2001 Regulation of the hypothalamic-pituitary-adrenocortical system in mice deficient for CRH receptors 1 and 2. Endocrinology 142 4946-4955. (doi:10.1210/en.142.11.4946) 
Rademaker MT, Charles CJ, Espiner EA, Fisher S, Frampton CM, Kirkpatrick CM, Lainchbury JG, Nicholls MG, Richards AM \& Vale WW 2002 Beneficial hemodynamic, endocrine, and renal effects of urocortin in experimental heart failure: comparison with normal sheep. Journal of the American College of Cardiology 40 1495-1505. (doi:10.1016/S0735-1097(02) 02170-8)

Rademaker MT, Charles CJ \& Richards AM 2007 Urocortin 1 administration from onset of rapid left ventricular pacing represses progression to overt heart failure. American Journal of Physiology. Heart and Circulatory Physiology 293 H1536-H1544. (doi:10.1152/ ajpheart.00377.2007)

Rademaker MT, Charles CJ, Nicholls MG \& Richards AM 2009 Urocortin 2 inhibits furosemide-induced activation of renin and enhances renal function and diuretic responsiveness in experimental heart failure. Circulation. Heart Failure 2 532-540. (doi:10.1161/CIRCHEARTFAILURE.109.861336)

Reyes TM, Lewis K, Perrin MH, Kunitake KS, Vaughan J, Arias CA, Hogenesch JB, Gulyas J, Rivier J, Vale WW et al. 2001 Urocortin II: a member of the corticotropin-releasing factor (CRF) neuropeptide family that is selectively bound by type 2 CRF receptors. PNAS $\mathbf{9 8}$ 2843-2848. (doi:10.1073/pnas.051626398)

Seres J, Bornstein SR, Seres P, Willenberg HS, Schulte KM, Scherbaum WA \& Ehrhart-Bornstein M 2004 Corticotropin-releasing hormone system in human adipose tissue. Journal of Clinical Endocrinology and Metabolism 89 965-970. (doi:10.1210/jc.2003-031299)

Sirianni R, Mayhew BA, Carr BR, Parker CR Jr \& Rainey WE 2005 Corticotropin-releasing hormone (CRH) and urocortin act through type $1 \mathrm{CRH}$ receptors to stimulate dehydroepiandrosterone sulfate production in human fetal adrenal cells. Journal of Clinical Endocrinology and Metabolism 90 5393-5400. (doi:10.1210/jc. 2005-0680)

Smith GW, Aubry JM, Dellu F, Contarino A, Bilezikjian LM, Gold LH, Chen R, Marchuk Y, Hauser C, Bentley CA et al. 1998 Corticotropin releasing factor receptor 1-deficient mice display decreased anxiety, impaired stress response, and aberrant neuroendocrine development. Neuron 20 1093-1102. (doi:10.1016/S0896-6273 (00) 80491-2)

Suda T, Kageyama K, Sakihara S \& Nigawara T 2004 Physiological roles of urocortins, human homologues of fish urotensin I, and their receptors. Peptides 25 1689-1701. (doi:10.1016/j.peptides.2004.03.027)

Tao J, Lin M, Sha J, Tan G, Soong TW \& Li S 2007 Separate locations of urocortin and its receptors in mouse testis: function in male reproduction and the relevant mechanisms. Cellular Physiology and Biochemistry 19 303-312. (doi:10.1159/000102393)

Timpl P, Spanagel R, Sillaber I, Kresse A, Reul JM, Stalla GK, Blanquet V, Steckler T, Holsboer F \& Wurst W 1998 Impaired stress response and reduced anxiety in mice lacking a functional corticotropin-releasing hormone receptor 1. Nature Genetics 19 162-166. (doi:10.1038/520)

Tsatsanis C, Dermitzaki E, Venihaki M, Chatzaki E, Minas V, Gravanis A \& Margioris AN 2007 The corticotropin-releasing factor (CRF) family of peptides as local modulators of adrenal function. Cellular and Molecular Life Sciences 64 1638-1655. (doi:10.1007/s00018-0076555-7)

Vale W, Spiess J, Rivier C \& Rivier J 1981 Characterization of a 41-residue ovine hypothalamic peptide that stimulates secretion of corticotropin and beta-endorphin. Science 213 1394-1397. (doi:10.1126/science.6267699)

Vale W, Rivier C, Brown MR, Spiess J, Koob G, Swanson L, Bilezikjian L, Bloom F \& Rivier J 1983 Chemical and biological characterization of corticotropin releasing factor. Recent Progress in Hormone Research 39 245-270.

Vaughan J, Donaldson C, Bittencourt J, Perrin MH, Lewis K, Sutton S, Chan R, Turnbull AV, Lovejoy D, Rivier C et al. 1995 Urocortin, a mammalian neuropeptide related to fish urotensin I and to corticotropin-releasing factor. Nature 378 287-292. (doi:10.1038/ $378287 \mathrm{a} 0)$

Vetter DE, Li C, Zhao L, Contarino A, Liberman MC, Smith GW, Marchuk Y, Koob GF, Heinemann SF, Vale W et al. 2002 Urocortindeficient mice show hearing impairment and increased anxiety-like behavior. Nature Genetics 31 363-369. (doi:10.1038/ng914)

Wang X, Su H, Copenhagen LD, Vaishnav S, Pieri F, Shope CD, Brownell WE, De Biasi M, Paylor R \& Bradley A 2002 Urocortindeficient mice display normal stress-induced anxiety behavior and autonomic control but an impaired acoustic startle response. Molecular and Cellular Biology 22 6605-6610. (doi:10.1128/MCB.22. 18.6605-6610.2002)

Xu J, Hennebold JD \& Stouffer RL 2006 Dynamic expression and regulation of the corticotropin-releasing hormone/urocortinreceptor-binding protein system in the primate ovary during the menstrual cycle. Journal of Clinical Endocrinology and Metabolism 91 1544-1553. (doi:10.1210/jc.2005-2776)

Yoshida-Hiroi M, Bradbury MJ, Eisenhofer G, Hiroi N, Vale WW, Novotny GE, Hartwig HG, Scherbaum WA \& Bornstein SR 2002 Chromaffin cell function and structure is impaired in corticotropinreleasing hormone receptor type 1-null mice. Molecular Psychiatry 7 967-974. (doi:10.1038/sj.mp.4001143)

Received in final form 20 January 2012

Accepted 6 February 2012

Made available online as an Accepted Preprint 6 February 2012 